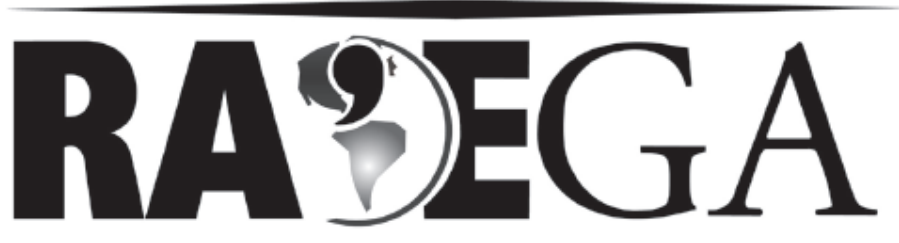

O ESPAÇO GEOGRÁFICO EM ANÁLISE

\title{
IDENTIFICAÇÃO DA FRAGILIDADE AMBIENTAL DA BACIA HIDROGRÁFICA DO ARROIO UVARANAL, COMO SUBSÍDIO AO PROJETO DE EXPANSÃO URBANA DE TELÊMACO BORBA - PR
}

\section{THE IDENTIFICATION OF THE ENVIRONMENTAL FRAGILITY OF THE HYDROGRAPHIC BASIN OF ARROIO UVARANAL, AS SUBSIDY TO URBAN EXPANSION OF TELEMACO BORBA - PR PROJECT}

\author{
Gustavo Conceição Bahr ${ }^{1}$ \\ Silvia Méri Carvalho²
}

\section{RESUMO}

Os estudos ambientais que tem entre seus parâmetros de análise as características físicas visam contribuir para minimizar as mudanças feitas pela sociedade na natureza. Para o desenvolvimento dessa pesquisa, foi utilizada a metodologia de identificação da fragilidade ambiental, proposta por Ross (2008) a fim de identificar as características ambientais de uma bacia hidrográfica, que abriga uma área proposta para expansão urbana no município de Telêmaco Borba-PR. Os resultados obtidos mostraram que a fragilidade potencial mais relevante na Bacia do Arroio Uvaranal está representada pela classe muito fraca, cobrindo $52,84 \%$ da área, razão da bacia apresentar, sobretudo, declividades baixas associadas com Latossolo Vermelho. Com relação à fragilidade emergente, os valores mais significativos também são referentes à classe muito fraca, ocupando $56,87 \%$ da Bacia do Uvaranal.

Palavras chave: Bacia Hidrográfica; Telêmaco Borba; Fragilidade Ambiental; Expansão Urbana.

\footnotetext{
${ }^{1}$ Mestre em Gestão do Território - UEPG. gustavo bahr@yahoo.com.br

2 Doutora em Geografia. UEPG - Universidade Estadual de Ponta Grossa. Ponta Grossa-PR silviameri@brturbo.com.br
} 


\section{ABSTRACT}

The environmental researches which use the physical characteristics as parameter of analysis, aim at finding ways to minimize this society changing on the nature. For this research to be developed, it was used a methodology that identify an environmental fragility, by Ross(2008), to identify environmental characteristics of hydrographic basin, that cover an area for urban expansion in Telêmaco Borba town, PR. The results show that the most relevant potential fragility of Uvaranal Hydrographic Basin is represented by very weak classes, covering $52,84 \%$ of its area and it's the reason of the basin show especially low declivity associated with Latossolo Vermelho. Concerning to the emergent fragility, the most significant values are also about low and medium classes, occupying $56,87 \%$ of the Uvaranal Basin.

Key words: Hydrographic Basin; Telêmaco Borba; Environmental Fragility; Urban Expansion.

\section{INTRODUÇÃO}

A sociedade urbana atual apresenta grande crescimento populacional, seja pelo incremento a partir de uma ocupação principalmente em busca de melhores condições de vida, ou devido ao crescimento natural. Dentro dessa conjuntura, as áreas urbanas tornam-se palco dos mais diversos problemas ambientais, pois muitas dessas cidades apresentam-se inchadas, com problemas no transporte coletivo, na produção de lixo, formação de ilhas de calor, ocorrência de enchentes e escorregamentos de terra, entre outros.

Devido a esse crescimento, ocorre a procura por novas áreas para serem ocupadas pela população. A escolha dessas áreas, se baseada em um conhecimento do meio físico, pode evitar muitos problemas, sobretudo de ordem ambiental, pois muitos desses são de origem geológica/geomorfológica. Essas escolhas devem ocorrer, preferencialmente, levando em conta as tecnologias disponíveis, técnicos qualificados e o envolvimento do Estado, em suas várias instâncias, imbuídos e dispostos a proporcionar qualidade de vida a sociedade.

Muitos problemas enfrentados pela população que reside nas cidades advém das características geológicas e geomorfológicas do sítio urbano. Sendo assim, torna-se fundamental que o planejamento urbano seja baseado em um conhecimento detalhado da área de instalação e sua expansão. 
A questão ambiental deve ser primordial quando nos referimos a expansão urbana, mas encarada com responsabilidade, pois percebe-se que na atualidade as instituições, sejam privadas ou públicas, possuem muita superficialidade com relação à temática, servindo muitas vezes apenas como uma bandeira, principalmente visando ganhos financeiros.

Com o intuito de analisar a fragilidade que a área apresenta e pode vir a apresentar devido a sua expansão, realizou-se essa pesquisa com aplicação de uma metodologia (ROSS, 2008) que utiliza como parâmetros de análise, as características do meio físico e as consequências que as interferências antrópicas realizadas nesse local podem ocasionar.

Para isso, Ross (2008) considera em sua análise a interpretação de elementos naturais, bem como os humanos. Com relação aos elementos naturais, fazem parte da análise os solos e a declividade, já os elementos humanos são caracterizados na maneira como a sociedade usa e ocupa a terra.

Dentro do conceito de fragilidade ambiental, destacam-se dois termos distintos: a fragilidade potencial e a fragilidade emergente. A fragilidade potencial é conceituada como sendo a vulnerabilidade natural de um ambiente em função de suas características físicas, baseada na declividade e o tipo de solo, enquanto que a fragilidade emergente além de considerar essas características, contempla também o grau de proteção dos diferentes tipos de uso e ocupação da terra (KAWAKUBO et al, 2005).

Dentre os estudos que utilizam a identificação da fragilidade ambiental, Spörl e Ross (2004) e Gonçalves et al (2009) destacam a importância que estes estudos possuem, pois proporcionam melhor definição das diretrizes e ações a serem implantadas, podendo servir de base para o zoneamento ambiental, além de fornecer subsídios à gestão do território.

Segundo Kawakubo et al (2005), o mapa de fragilidade ambiental constitui uma das ferramentas utilizadas pelos órgãos públicos na elaboração do planejamento ambiental. Portanto, esse mapeamento constitui uma importante ferramenta no auxílio de um ordenamento adequado do meio, indicando as áreas mais favoráveis a sua ocupação. 
Para Donha, Souza e Sumagosto (2006) é necessário que os planejamentos contemplem todas as instâncias, não só o socioeconômico, mas também a questão ambiental. Dentro dessa perspectiva, não se deve levar em conta apenas as potencialidades, mas principalmente as fragilidades das áreas com intervenções antrópicas. Os autores destacam ainda a importância de estudos na área ambiental, principalmente aqueles que realizam a identificação da fragilidade ambiental.

Muitos trabalhos são baseados, sobretudo, em análises para identificação de processos relacionados a degradação dos solos. As análises procuram, também, buscar respostas para um planejamento que considere as características relacionadas à forma como ocorre o uso e ocupação da terra. Portanto, a apropriação consciente do espaço visa evitar alguns problemas que afetam direta ou indiretamente a sociedade.

A expansão urbana ocorre, na maior parte das vezes, sem 0 conhecimento das características físicas da área, informações essas que auxiliam na tomada de decisões da alocação da infraestrutura do local. Esse conhecimento é a base quando o assunto é a ampliação do sítio urbano, portanto a fase de levantamento é de extrema importância, pois pode minimizar, ou mesmo anular, a existência de problemas futuros.

Uma indicação de extrema importância, tanto no ambiente rural como no urbano, é a manutenção da vegetação, sendo "a defesa natural de um terreno contra a erosão" (BERTONI; LOMBARDI NETO, 2008, p. 59). A vegetação funciona como proteção do solo, não deixando que a chuva atinja, e posteriormente desagregue as partículas de solo, levando assim à ocorrência ou intensificação dos processos erosivos.

Esta defesa possui papel mais eficiente no caso de vegetação nativa, mas também obtêm êxito em casos como os reflorestamentos. Em se tratando de Pinus spp., que se apresentam de maneira densa, as folhas das árvores exercem papel de bloqueio das gotas de chuva, evitando assim que atinjam diretamente o solo, posteriormente ela cai em menor velocidade e encontra uma proteção formada por folhas secas das árvores que ficam acumuladas em grandes quantidades sobre o solo. Assim sendo, essa água infiltra sem exercer 
um papel agressivo, ou seja, não atinge com poder para desagregar os grãos de solo.

Cavalheiro (2009) destaca que as principais alterações relacionadas a vegetação em áreas urbanizadas é que essa apresenta-se bastante alterada, além de um deserto de epífitas e uma vegetação ruderal abundante.

Se medidas como a manutenção da vegetação não forem tomadas, podem ocorrer os impactos ambientais negativos. Alguns destes são de ocorrência específica no espaço urbano, como a ocorrência das enchentes ocasionadas pela impermeabilização do solo, a ocupação das encostas com loteamentos e edificações, o que aumenta o risco de deslizamentos, a canalização e retificação dos canais fluviais com percurso nas áreas urbanas, a invasão das áreas periféricas e intraurbanas não edificáveis, com instalação de favelas, e a proliferação dos depósitos de lixo em locais não apropriados, entre outros (VIEIRA; CUNHA, 2009).

Para Cavalheiro (2009) o aumento da eutrofização é no sentido das áreas urbanas em direção às áreas periféricas, enquanto que os solos decompostos e impermeabilizados aumentam em sentido oposto, portanto, das áreas mais periféricas em direção as áreas centrais.

Com a abertura de novas áreas onde serão instaladas as edificações, o primeiro passo é o desmatamento, resultando no fornecimento de materiais que serão erodidos e carregados para os cursos d'água, podendo gerar o assoreamento e riscos de enchentes. Tudo isso com a grande intensidade de movimentação de terra, característico do processo de urbanização (CAVALHEIRO, 2009).

Os índices mais elevados de erosões ocorrem durante o processo de construção da cidade, com grande movimentação de máquinas e escavações, além da exposição dos solos. As taxas erosivas podem ser maiores em um ano de construção da cidade do que em dez se comparada a um ambiente rural (GOUDIE apud GUERRA; MENDONÇA, 2004).

Ainda com relação a grande intensidade das erosões durante o processo de expansão urbana, Santoro (2009, p. 60) destaca que: 


\begin{abstract}
Nas áreas urbanas, a erosão avança agressivamente nos setores de expansão das cidades, por meio da abertura de novos loteamentos, os quais exigem para a sua implantação, grande movimentação e exposição de solos. Estes terrenos, sem a proteção da cobertura vegetal e das camadas superficiais do solo, tornam-se vulneráveis à ação das chuvas e do escoamento superficial das águas pluviais, propiciando a instalação da erosão acelerada. Associados aos aspectos da implantação destes empreendimentos, a escolha de locais geotecnicamente inadequados, falta de infra-estrutura urbana, traçado inadequado do sistema viário e sistemas de drenagem mal concebidos e mal executados aceleram a ocorrência dos processos erosivos.
\end{abstract}

Dias (2006) destaca que a expansão urbana ocorre com segurança em declividades de até $30 \%$, e uma ocupação imprópria poderá resultar em áreas de instabilidades ambientais, destacando ainda que a infraestrutura básica já deve estar instalada antes do início das ocupações.

A infraestrutura é importante na qualidade de vida da população, porque a sua instalação, manutenção e modernização é uma questão de política habitacional, devendo contemplar a sociedade como um todo, ao contrário da satisfação de pequenos grupos ou interesses particulares.

Outras questões destacadas a respeito da expansão urbana, ou seja, a transformação de uma área natural em urbana, segundo Cavalheiro (2009), são as mudanças referentes ao clima, no sentido de aumento do ar poluído, do ar aquecido, da umidade relativa e redução das trocas de ar é com relação a insolação, albedo, umidade relativa e nebulosidade do vento que são maiores no campo, enquanto que precipitação e temperaturas são maiores nas cidades. Ainda ocorre perturbação significativa nos fluxos de ar intraurbano, ocasionado pelo trânsito intenso, concentração de edifícios e pessoas, indústrias, retirada da vegetação, novas formas topográficas e produção artificial de calor (BRANDÃO, 2009). Segundo o mesmo autor:

A urbanização é o processo de conversão do meio físico natural para o assentamento urbano, acompanhada de drásticas e irreversíveis mudanças do uso do solo, gerando uma nova configuração da superfície aerodinâmica e das propriedades radiativas, da umidade e da qualidade do ar (BRANDÃO, 2009, p. 53).

A ampliação da área urbana acarreta mudanças significativas no ambiente, devido as suas construções e pavimentações. Portanto, o conhecimento do meio físico pode minimizar problemas que afetam a população, sendo menos impactante pensar a cidade antes de sua construção do que posteriormente aos problemas já existentes. 
Sendo assim, os trabalhos que tem como objeto de análise a relação sociedade - natureza visam uma melhor conservação dos aspectos naturais. Assim, os estudos de identificação da fragilidade ambiental fornecem respostas quanto a melhor utilização das áreas, podendo encontrar espaços com maior ou menor fragilidade, sejam naturais, ou mesmo com a interferência antrópica.

O conhecimento das características do ambiente é de extrema importância, pois a identificação de seus aspectos é o início da prevenção de algumas situações e, consequentemente evitar alguns problemas futuros. Este conhecimento deve ter a amplitude com relação às potencialidades ou qualidades, bem como as fragilidades presentes em uma determinada área.

Pretende-se com o trabalho, demonstrar a fragilidade ambiental na Bacia Hidrográfica do Arroio Uvaranal e dentro desta, o local onde se encontra prevista a área de expansão urbana de Telêmaco Borba. Essa proposta se torna importante pelo fato de serem locais de futuros projetos urbanísticos, devido principalmente a sua localização estratégica no município. Sendo assim, a área não poderia ser analisada individualmente, pois "a visão sistêmica e integrada do ambiente está implícita na adoção desta unidade fundamental" (BOTELHO; SILVA, 2004, p. 153).

\section{CARACTERIZAÇÃO DA ÁREA E PROCEDIMENTOS METODOLÓGICOS}

A Bacia Hidrográfica do Arroio Uvaranal está localizada no município de Telêmaco Borba (Figura 1), que por sua vez situa-se na mesorregião 5 , nomeada Centro-Oriental (IBGE, 2010), pertencente ainda à Associação dos Municípios dos Campos Gerais, junto a outros 17 municípios (AMCG, 2010).

$\mathrm{O}$ traçado original da cidade de Telêmaco Borba foi concebido através de um projeto de parcelamento elaborado pelo arquiteto e urbanista Max Staudacher, sendo que a área de 300 alqueires foi dividida em 200 quadras, 5.478 lotes e 73 chácaras. Esse projeto foi caracterizado por eixos ordenadores através de vias estruturais ligando os diversos setores da cidade, utilizando-se da topografia através dos pontos de divisão de águas ou margeando os fundos de vale e arroios (TELÊMACO BORBA, 2006a). 
O projeto levou em conta a topografia, a hidrografia e a vegetação da cidade, onde as áreas com altas declividades e próximas as nascentes ficaram reservadas para a implantação de chácaras, locais onde supostamente 0 adensamento é menor, permitindo assim a preservação dessas áreas com um grande cinturão verde, margeando a cidade, e contendo a expansão urbana, além de servir para áreas de lazer e cultivos de hortifrutigranjeiros, para o abastecimento da cidade.

A Bacia Hidrográfica do Arroio Uvaranal possui ocupação urbana no seu baixo curso, sendo que o início desta é paralelo ao processo de Telêmaco Borba, com a construção da área central da cidade em 1951. Posteriormente, em 1958, foi construído o Núcleo Residencial JK (Cem Casas), o primeiro

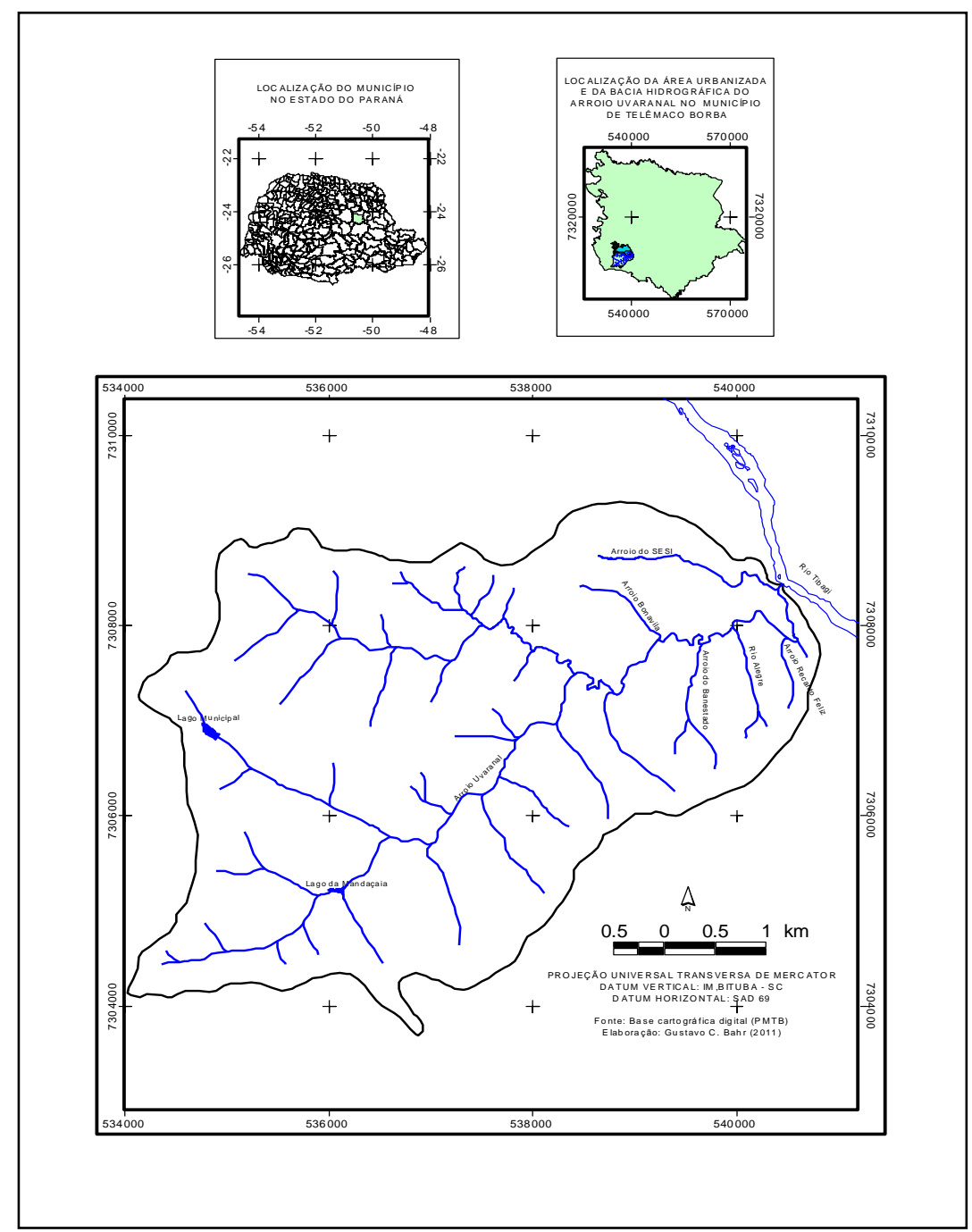

Figura 1: Bacia Hidrográfica do Arroio Uvaranal, Telêmaco Borba - PR. 
conjunto habitacional da cidade. Na década de 1960 a ocupação da bacia acontece com a construção da Vila Santa Rita, em 1962 e Vila São Francisco I, em 1966, sendo que ambos são frutos de loteamentos particulares. No ano de 1967 foram construídas a Vila BNH e Vila Nossa Senhora de Fátima, sendo os dois conjuntos habitacionais. Na década seguinte, de 1970, a ocupação na bacia continua com a construção da segunda fase das Vilas Nossa Senhora de Fátima (1976) e BNH (1977). Já em 1986 é construída na bacia o Conjunto Residencial Tibagi, o primeiro conjunto vertical da cidade em um loteamento particular. (TELÊMACO BORBA, 2006a).

O processo de ocupação na Bacia do Arroio Uvaranal por meio de loteamentos encerra-se na década de 1990, quando ocorre a construção da Vila São Francisco II, no ano de 1990, Jardim São Rafael, em 1993, e Jardim Kroll, em 1998. Os loteamentos realizados nessa década foram edificados sobre o plano base de parcelamento em loteamentos particulares.

O Arroio Uvaranal apresenta controle estrutural, fato que se observa em vários trechos de seu curso, com a ocorrência de um padrão de drenagem paralelo. $\mathrm{Na}$ área urbanizada, o arroio é caracterizado pela presença de grande concentração de lixo nas águas e em suas margens, esgotos lançados in natura e com inúmeros trechos sem a presença de vegetação ciliar. Em trabalhos de campo constatou-se a existência de processos erosivos, tanto próximo aos cursos d'água, como também em algumas estradas, além de casos de ocupações que estão localizadas na APP do Arroio Uvaranal.

Dentre os aspectos levantados pelo Plano Diretor de Desenvolvimento Urbano - PDDU-TB (TELÊMACO BORBA, 2006b), uma das questões discutidas foi à escolha de uma área para expansão urbana. Esta escolha baseou-se na procura de áreas próximas ao centro da cidade, evitando assim que o Estado tivesse gastos mais elevados na alocação de infraestrutura, além de funcionar como um acesso alternativo à cidade.

A expansão demanda 0 uso de áreas antes ocupadas por outras atividades, e o estudo destas deve ser efetuado antes da ocupação, pois podem minimizar, ou mesmo evitar a degradação ambiental. 
A área apontada pelo Plano Diretor de Desenvolvimento Urbano PDDU-TB (TELÊMACO BORBA, 2006b) para expansão urbana de Telêmaco Borba, possui uma área de $2,65 \mathrm{~km}^{2}$ e está localizada a sudoeste da cidade. Pertence em sua maior parte às Indústrias Klabin e é coberta por reflorestamento, mata, solo exposto, campo e uso industrial.

Com a perspectiva de evitar alguns problemas ambientais, foram criadas pelo Estado áreas com usos restritos. $\mathrm{Na}$ área de expansão urbana, existem as Áreas de Interesse Ambiental (AIA) e de Preservação Permanente (APP), sendo que a AIA é estabelecida pelo Zoneamento Ambiental de Telêmaco Borba (TELÊMACO BORBA, 2006b), e a APP pelo Código Florestal (BRASIL, 1965).

No que diz respeito às questões ambientais, à legislação estabelecida no PDDU-TB (TELÊMACO BORBA, 2006b), em seu o Art. 226 consta

\begin{abstract}
A organização e a expansão urbana no Município deverá ser compatibilizada com as diretrizes do planejamento e zoneamento ambiental, englobando todos os recursos e assegurando o controle dos potenciais riscos e prejuízos ao Meio Ambiente e respectivas populações.
\end{abstract}

Para a Área de Interesse Ambiental, o PDDU-TB (TELÊMACO BORBA, 2006b) aponta em seu Art. 227 que:

\footnotetext{
Para fins de defesa, preservação, conservação e recuperação ambiental, 0 Município será subdividido de acordo com o zoneamento ambiental, considerados os aspectos geológicos, geomorfológicos, pedológicos, biológicos, de ocupação atual e riscos potenciais, nas [...] áreas denominadas de "Áreas de Interesse Ambiental".
}

A Área de Preservação Permanente é estabelecida pelo Código Florestal (BRASIL, 1965), por meio da Lei $4.771 / 65$ e a medida provisória 2.166/01 (BRASIL, 2001). No caso específico da área de expansão urbana de Telêmaco Borba, são consideradas APP as áreas marginais de 30 metros em relação aos cursos d'água e um raio de 50 metros a partir das nascentes.

Essas duas áreas protegidas por lei (APP e AIA), que apresentam relevância ambiental, são compostas por Floresta Ombrófila Mista e Floresta Estacional Semi-Decidual, estando em boas condições de conservação. Durante a fase de implementação do loteamento, e a instalação urbana, estas 
áreas devem ser preservadas e caso utilizadas, devem ter projetos de manutenção da vegetação.

Com relação à metodologia utilizada, a identificação da fragilidade ambiental é baseada na interpretação de elementos naturais, bem como elementos humanos, sendo que para determinar a fragilidade ambiental Ross (2008) sugere a elaboração de alguns documentos, dentre eles:

> carta de declividade média das vertentes com cinco classes;

$>$ carta de pedologia;

$>$ carta de uso da terra e cobertura vegetal;

$>$ análise dos dados pluviométricos.

A metodologia ainda sugere análises de informações sobre a geologia e o clima. Estas são informações adicionais, utilizados para a análise-síntese, com a finalidade de dar maior precisão aos resultados do trabalho.

$\mathrm{Na}$ realização dos mapeamentos e elaboração do banco de dados para o presente trabalho, foi utilizado o software ArcView $G S^{\circledR}$ 3.2, sistema gerenciador que auxiliou na entrada, armazenamento, tratamento e saída de dados para realização do trabalho.

Para confecção do material utilizado na determinação da fragilidade ambiental foi utilizado, inicialmente, o recorte espacial da Bacia Hidrográfica do Arroio Uvaranal, e posteriormente, foi realizado um recorte específico da área de expansão urbana.

Fez-se uso dos seguintes materiais:

> imagem de satélite QuickBird, multiespectral, resolução espacial 2,44 metros, ano 2008;

> base cartográfica digital georreferenciada com os seguintes temas: hidrografia, curvas de nível e vias de circulação (escala 1:50.000);

$>$ carta de solos, em formato digital (escala 1:20.000). 
A base cartográfica digital e a imagem de satélite utilizada para realização do trabalho foram cedidas da Prefeitura Municipal de Telêmaco Borba. A base cartográfica já se encontrava no formato shapefille (.shp), compatível com a operacionalização do software. A imagem foi registrada em 03 de fevereiro de 2008, pelo satélite QuickBird, série de satélites comerciais controlados pela empresa DigitalGlobe, com aplicações diretas na área de mapeamentos urbanos, dinâmicas de uso e ocupação da terra, entre outras, isso devido a alta resolução espacial oferecida pelo satélite (EMBRAPA, 2010).

Com relação as informações pedológicas da Bacia Hidrográfica do Arroio Uvaranal, utilizou-se mapa cedido pelas Indústrias Klabin. Esse mapa digital encontrava-se em formato shapefille (.shp) e já georreferenciado. A área em questão é composta pelas seguintes classes de solos: Argissolo Vermelho, Cambissolo Háplico, Latossolo Vermelho e Neossolo Quartzarênico.

O ponto de partida do trabalho foi a construção da carta base da bacia hidrográfica. Esta carta teve início com a delimitação da bacia, com a utilização de mapa digital de curvas de nível, hidrografia e o software citado. O mapa teve correção em relação a alguns detalhes com a construção e análise de um Modelo Digital de Elevação (MDE), material que fornece melhor visualização referente aos divisores d'água.

Posteriormente, elaborou-se o mapa clinográfico da bacia hidrográfica, utilizando o aplicativo 3D Analyst, do software ArcView GIS ${ }^{\circledR}$ 3.2. Esta carta foi dividida em 5 classes, conforme Ross (2008), sendo assim classificada: até $6 \%$, de 6 a $12 \%$, de 12 a $20 \%$, de 20 a $30 \%$ e mais de $30 \%$.

Para a realização do mapeamento de uso e ocupação da terra na Bacia Hidrográfica do Arroio Uvaranal, também se fez uso das técnicas de geoprocessamento e as classes de usos adotadas foram adaptadas do IBGE (2006), ficando assim estabelecidas: área urbanizada, área industrial, campo, corpos d'água, mata, reflorestamento e solo exposto.

Após a elaboração das cartas de solo, declividade e uso da terra, cada uma recebeu identificações referentes aos graus de fragilidades, sendo compostas por cinco classes: muito fraca, fraca, média, forte e muito forte. 
Com relação a carta de declividade do relevo, as classes de fragilidades ficaram assim estabelecidas, conforme Tabela 1:

Tabela 1. Fragilidade das classes de declividade - Bacia do Arroio Uvaranal

\begin{tabular}{c|c}
\hline CLASSES DE FRAGILIDADE & CLASSES DE DECLIVIDADE \\
\hline Muito fraca & até $6 \%$ \\
\hline Fraca & de 6 a $12 \%$ \\
\hline Média & de 12 a $20 \%$ \\
\hline Forte & de 20 a $30 \%$ \\
\hline Muito forte & acima de $30 \%$ \\
\hline
\end{tabular}

Fonte. Ross (2008)

Da mesma forma, a carta de solos recebeu classes de acordo com sua fragilidade ao processo de erosão, conforme Tabela 2.

Tabela 2. Fragilidade das classes de solos - Bacia do Arroio Uvaranal

\begin{tabular}{c|c}
\hline CLASSES DE FRAGILIDADE & TIPOS DE SOLOS \\
\hline Muito fraca & Latossolo Vermelho \\
\hline Média & Argissolo Vermelho \\
\hline Forte & Cambissolo Háplico \\
\hline Muito forte & Neossolo Quartzarênico \\
\hline
\end{tabular}

Fonte. Adaptado de Santos (2005) e Ross (2008)

As classes de fragilidade ambiental de uso e ocupação da terra foram determinadas de acordo com o grau de proteção que cada uma oferece, conforme Tabela 3:

Tabela 3. Graus de proteção em relação ao tipo de cobertura vegetal/uso da terra Bacia do Arroio Uvaranal

\begin{tabular}{c|c}
\hline GRAUS DE PROTEÇÃO & TIPO DE COBERTURA VEGETAL/USO DA \\
TERRA \\
\hline Muito forte & Mata \\
\hline & Área urbanizada \\
Forte & Reflorestamento \\
Uso industrial
\end{tabular}

Fonte. Adaptado de Santos (2005), Ross (2004) e Ross (2008) 
O cruzamento das cartas para determinação da fragilidade ambiental foi realizado utilizando o software ArcView GIS $^{\circledR}$ 3.2, sobrepondo as informações. Inicialmente as informações de solos e declividade para determinação da fragilidade potencial, e posteriormente este resultado com o uso e ocupação da terra, resultando assim na fragilidade emergente.

Apesar dos elementos citados serem essenciais para determinação da fragilidade ambiental, outras informações auxiliam na interpretação dos resultados. Essas são referentes à geologia e o clima, sendo imprescindível às análises geológicas em conjunto com as informações climáticas, sobretudo relacionadas à distribuição e intensidade das chuvas, sendo a pluviosidade um dos "fatores decisivos no processo de intemperismo das rochas e formação dos solos, fundamentais para a análise da vulnerabilidade ambiental" (MELO; SANTOS, 2010, p. 22).

\section{RESULTADOS E DISCUSSÕES}

A fragilidade potencial considera os aspectos naturais, caracterizando 0 equilíbrio dinâmico natural, sem considerar as influências da sociedade em uma determinada área. Na Bacia Hidrográfica do Uvaranal ela foi quantificada a partir do cruzamento de informações referentes aos tipos de solos e as declividades do relevo, e foram determinadas quatro classes: muito fraca, fraca, média e forte, conforme Tabela 4.

Tabela 4. Fragilidade potencial da Bacia Hidrográfica do Arroio Uvaranal, Telêmaco Borba - PR

\begin{tabular}{c|c|c}
\hline $\begin{array}{c}\text { GRAU DE FRAGILIDADE } \\
\text { POTENCIAL }\end{array}$ & $\begin{array}{c}\text { ÁREA } \\
\mathbf{( k m}^{\mathbf{2}} \text { ) }\end{array}$ & $\begin{array}{c}\text { PORCENTAGEM } \\
(\%)\end{array}$ \\
\hline Muito fraca & 12,52 & 52,83 \\
\hline Fraca & 3,85 & 16,24 \\
\hline Média & 6,47 & 27,30 \\
\hline Forte & 0,83 & 3,50 \\
\hline
\end{tabular}

\footnotetext{
${ }^{3}$ A área total da bacia hidrográfica do Arroio Uvaranal é $23,70 \mathrm{~km}^{2}$. No total apresentado na Tabela 13, não está contabilizado $0,03 \mathrm{~km}^{2}(0,13 \%)$, correspondente aos corpos d'água.
} 
A classe de fragilidade potencial mais representativa é a muito fraca, estando disposta por todos os setores da bacia hidrográfica (Figura 2). Esta classe corresponde principalmente as áreas que apresentam declividades do relevo de até $12 \%$ associadas a Latossolo Vermelho, ou seja, áreas com

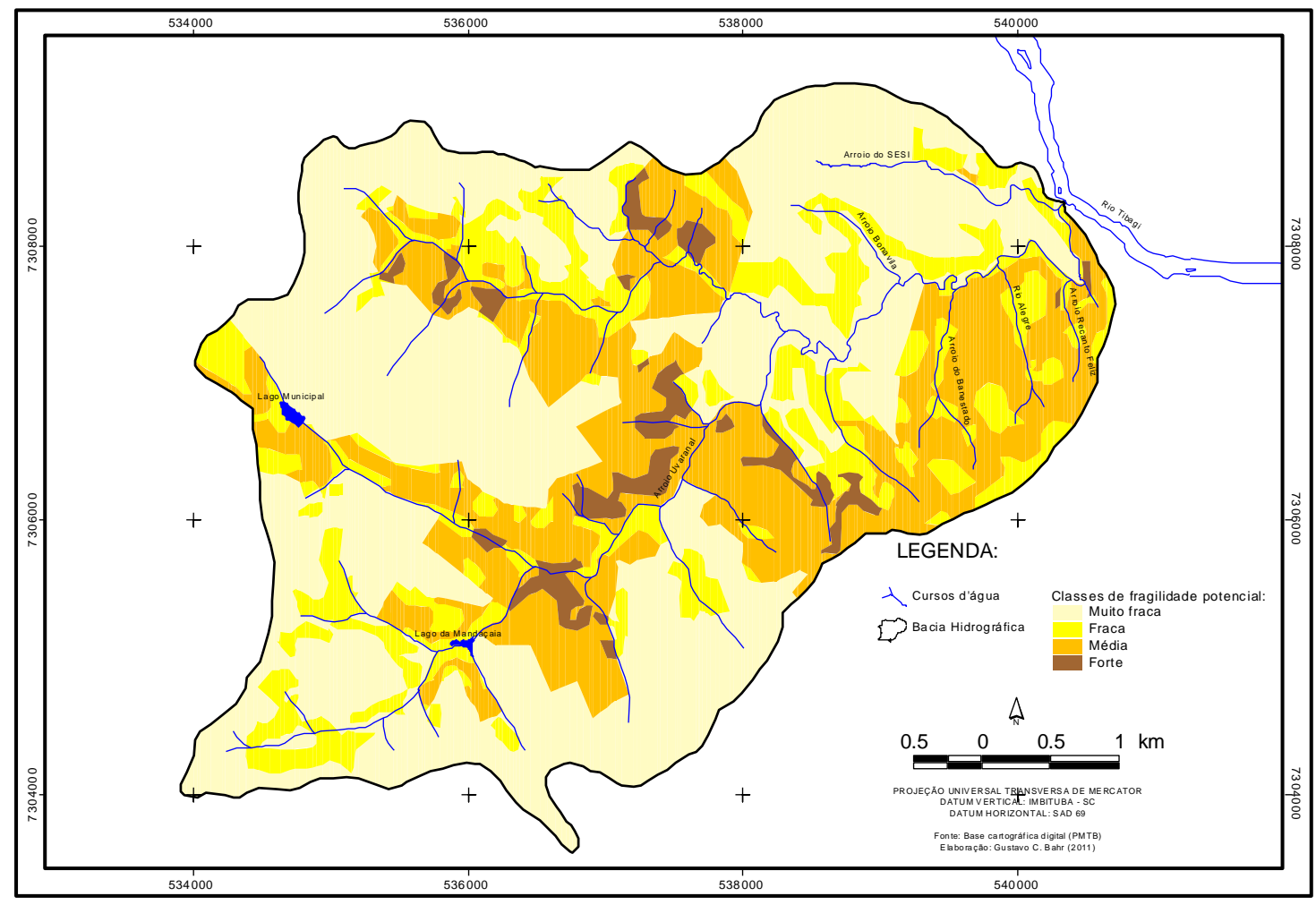

Figura 2. Fragilidade potencial da Bacia Hidrográfica do Arroio Uvaranal, Telêmaco Borba - PR

baixas declividades e solos profundos, com elevada permeabilidade e bem drenados.

Posteriormente, outra classe de fragilidade potencial que apresenta área expressiva é a fragilidade média. A distribuição espacial desta classe de fragilidade ocorre principalmente nas proximidades dos cursos d'água, com concentração maior na porção leste da bacia.

A classe de fragilidade potencial média é resultado, principalmente, da associação entre declividades de 6 a 20\% com Cambissolo Háplico, mas também pode ser encontrada em áreas com Neossolo Quartzarêncio e 
declividades até $12 \%$. Esta classe é um cruzamento de informações de solos que apresentam horizonte A raso, pobre em matéria orgânica, textura francoargilosa à muito argilosa, com áreas de relevo ondulado, onde pode-se encontrar uma topografia pouco movimentada, e também solos pouco espessos e declividade muito fraca.

$\mathrm{Na}$ sequência encontram-se na Bacia do Uvaranal áreas com grau de fragilidade potencial fraca, o que corresponde a $3,85 \mathrm{~km}^{2}$. A referida classe está relacionada preferencialmente com áreas de Latossolo Vermelho e declividades de 12 a 30\%, áreas de Argissolo Vermelho e declividades de 6 a $20 \%$, mas também pequena área com Cambissolo Háplico em declividades de até $6 \%$.

A fragilidade potencial classificada como forte é encontrada em $0,83 \mathrm{~km}^{2}$. Esta classe de fragilidade potencial é encontrada em áreas com declividades maiores que $20 \%$ e Cambissolo Háplico, além de áreas com Neossolo Quartzarênico e declividades entre 12 e 20\%.

Se considerarmos a fragilidade potencial da Bacia do Uvaranal, observase que $96,37 \%$ da área está representada pelas classes muito fraca a média. Isto se deve ao fato da bacia apresentar declividades baixas, com $82,61 \%$ da área possuindo declividades de até $12 \%$, estando, sobretudo associadas com Latossolo Vermelho, que cobre $60,04 \%$ do total. Esta classe de solo é caracterizada por grande profundidade e por serem bem drenados. Com essas características de solos e declividade, e os valores pluviométricos, a erosividade também será baixa, portanto, apresentando baixa susceptibilidade aos processos erosivos.

A fragilidade emergente é a relação entre a fragilidade potencial, identificada a partir da relação de informações de solos e declividade, acrescida da interferência antrópica, ou seja, a forma como a sociedade usa e ocupa a terra.

Conforme a Tabela 5, observa-se que a classe mais representativa da área da Bacia do Uvaranal é a muito fraca. A classe está distribuída por todos os setores da bacia hidrográfica, principalmente próximo aos divisores da mesma. 
A classe de fragilidade emergente muito fraca ocorre em áreas onde a cobertura vegetal corresponde à mata e a fragilidade potencial é muito fraca $\mathrm{e}$ fraca. Pode ainda ocorrer em áreas com fragilidade potencial muito fraca, associadas com o uso industrial, urbanizado, mas especialmente em reflorestamentos. (Figura 3).

Tabela 5. Fragilidade emergente da Bacia Hidrográfica do Arroio Uvaranal, Telêmaco Borba - PR

\begin{tabular}{c|c|c}
\hline $\begin{array}{c}\text { GRAU DE FRAGILIDADE } \\
\text { EMERGENTE }\end{array}$ & $\begin{array}{c}\text { ÁREA }^{4} \\
\left.\mathbf{( k m}^{2}\right)\end{array}$ & $\begin{array}{c}\text { PORCENTAGEM } \\
(\%)\end{array}$ \\
\hline Muito fraca & 13,48 & 56,87 \\
\hline Fraca & 8,88 & 37,47 \\
\hline Média & 1,19 & 5,02 \\
\hline Forte & 0,12 & 0,51 \\
\hline
\end{tabular}

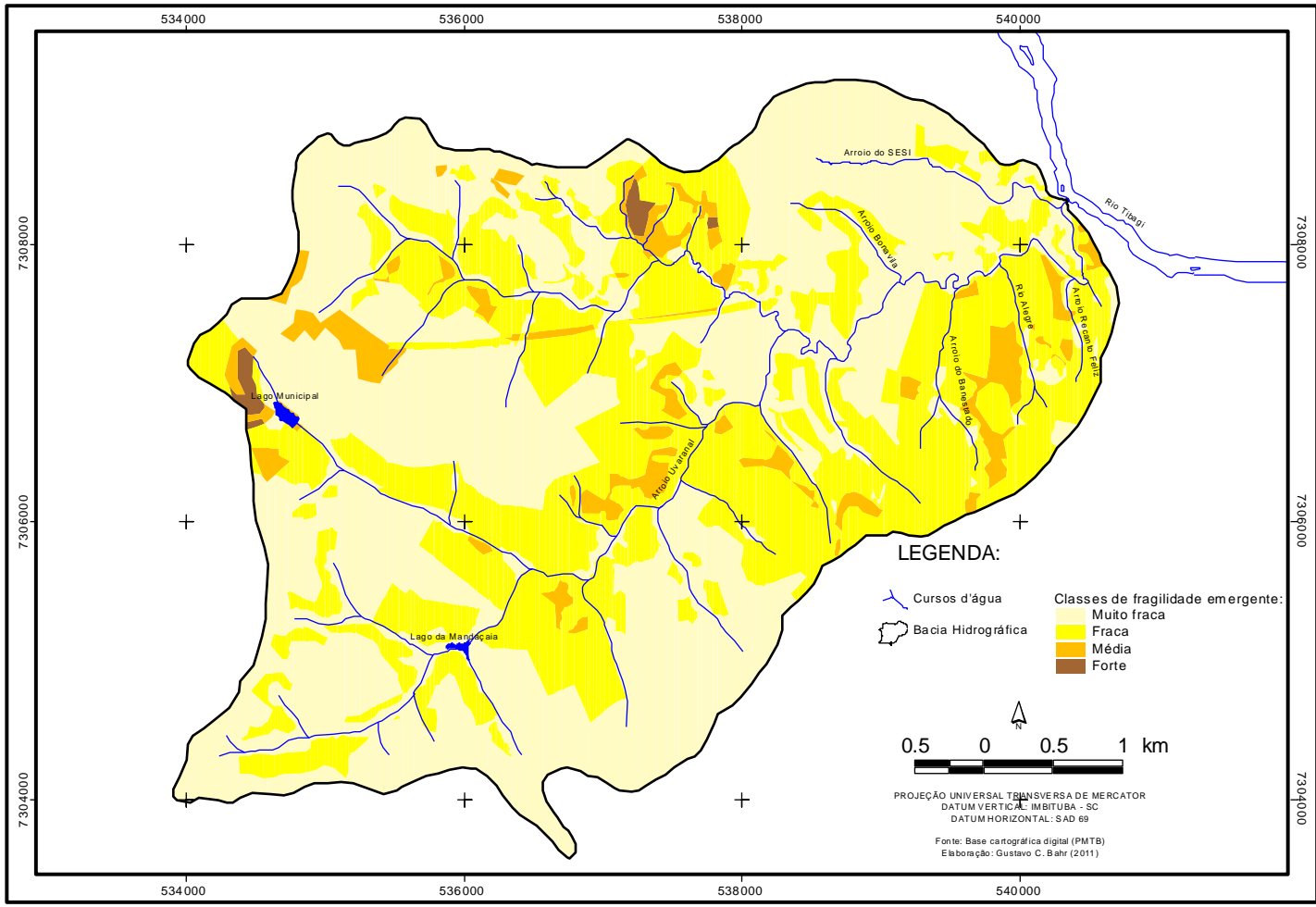

Figura 3. Fragilidade emergente da Bacia Hidrográfica do Arroio Uvaranal, Telêmaco Borba PR

\footnotetext{
${ }^{4}$ A área total da bacia hidrográfica do Arroio Uvaranal é $23,70 \mathrm{~km}^{2}$. No total apresentado na Tabela 14, não está contabilizado $0,03 \mathrm{~km}^{2}(0,13 \%)$, correspondente aos corpos d'água.
} 
Na sequência, aparece a fragilidade emergente fraca, também podendo ser encontrada por toda a área da bacia. Esta classe foi identificada em todos os usos da terra, a exceção das áreas com solo exposto. As associações para esta determinação são de mata em fragilidade potencial média e forte, em área urbanizada, industrial e de reflorestamento, associadas à fragilidade potencial fraca e média, e também ocorrem em áreas de campo e fragilidade potencial muito fraca e fraca.

Posteriormente, tem-se a classe de fragilidade emergente média, localizada em todos os setores da Bacia do Uvaranal, estando associada a todos os tipos de uso da terra identificados na área, a exceção das áreas com mata. A referida classe de fragilidade emergente ocorre em áreas com fragilidade potencial forte onde o uso e ocupação é área urbanizada, industrial e reflorestamento, podendo ainda ser encontrada em áreas com campo e fragilidade potencial média ou forte e também onde o solo é exposto, sendo que nesse caso a associação é com fragilidade potencial muito fraca e fraca.

Por fim, tem-se a classe de fragilidade emergente forte, que se encontra na bacia em alguns pequenos pontos isolados, a norte e a oeste. Essa classe de fragilidade emergente é resultado da combinação de áreas com solo exposto e fragilidade potencial média e forte.

Com relação à fragilidade emergente, resultante do cruzamento da fragilidade potencial, acrescida das informações do uso e ocupação da terra, percebe-se que 99,36\% da área da Bacia do Uvaranal está representada pelas classes muito baixa a média. Esta identificação é proveniente do valor expressivo da fragilidade potencial muito fraca a média, em conjunto com uso da terra que propiciam certa proteção ao solo.

A concretização de um empreendimento referente à ampliação de área urbana deve estar amparada em estudos técnicos que caracterizem e analisem o local, indicando as suas potencialidades e fragilidades. No caso da ampliação da área urbana de Telêmaco Borba, as mudanças referentes ao uso, ocorrerão nas áreas ocupadas por reflorestamento convertidas para o uso urbanizado.

Com a modificação de uso rural para uso urbanizado, de áreas com reflorestamentos para impermeabilizadas, a paisagem será constituída por vias 
de asfaltos e poliédricos, telhados e calçamentos das residências, serviços e comércio. Importante salientar que não é toda área urbana que possui pavimentação, e consequente será uma área impermeabilizada. Áreas como praças, parques e jardins, além de alguns fragmentos encontrados em quintais de residências, permitem que ocorra a infiltração das águas da chuva e possuem um caráter diferenciado do citado.

De acordo com o Zoneamento Urbano de Telêmaco Borba (TELÊMACO BORBA, 2006b), em toda a cidade a taxa de permeabilidade mínima é $10 \%$. Não existe um zoneamento para a área de expansão, que pode ainda ser criado levando-se em conta esta problemática.

Portanto, visando servir de subsídio para os estudos referentes à ampliação da área urbanizada, foi realizado, também, mapeamento e análise da fragilidade potencial e emergente na área específica destinada para expansão.

A área prevista para expansão urbana de Telêmaco Borba possui 2,65 $\mathrm{km}^{2}$, sendo que a APP possui $0,30 \mathrm{~km}^{2}$ e a AIA $0,36 \mathrm{~km}^{2}$. Sendo assim, de área efetiva para ampliação da área urbana, corresponde a $1,99 \mathrm{~km}^{2}$, sendo que os dados apresentados a seguir, referentes à fragilidade potencial e emergente da área de expansão, são baseados nessa área de uso efetivo. Com relação à fragilidade ambiental da área, pode-se observar a Tabela 6 e Figuras 4 e 5.

Tabela 6. Fragilidade ambiental na área de expansão urbana de Telêmaco Borba - PR

\begin{tabular}{c|c|c|c|c}
\hline \multirow{2}{*}{$\begin{array}{c}\text { CLASSES DE } \\
\text { FRAGILIDADE }\end{array}$} & \multicolumn{2}{|c|}{$\begin{array}{c}\text { GRAU DE FRAGILIDADE } \\
\text { POTENCIAL }\end{array}$} & $\begin{array}{c}\text { GRAU DE FRAGILIDADE } \\
\text { EMERGENTE }\end{array}$ \\
\cline { 2 - 5 } & $\mathbf{k m}^{2}$ & $\%$ & $\mathbf{k m}^{2}$ & $\%$ \\
\hline Muito fraca & 1,15 & 57,79 & 0,98 & 49,25 \\
\hline Fraca & 0,30 & 15,08 & 0,80 & 40,20 \\
\hline Média & 0,49 & 24,62 & 0,21 & 10,55 \\
\hline Forte & 0,05 & 2,51 & 0,00 & 0,00 \\
\hline TOTAL & 1,99 & 100 & 1,99 & 100 \\
\hline
\end{tabular}




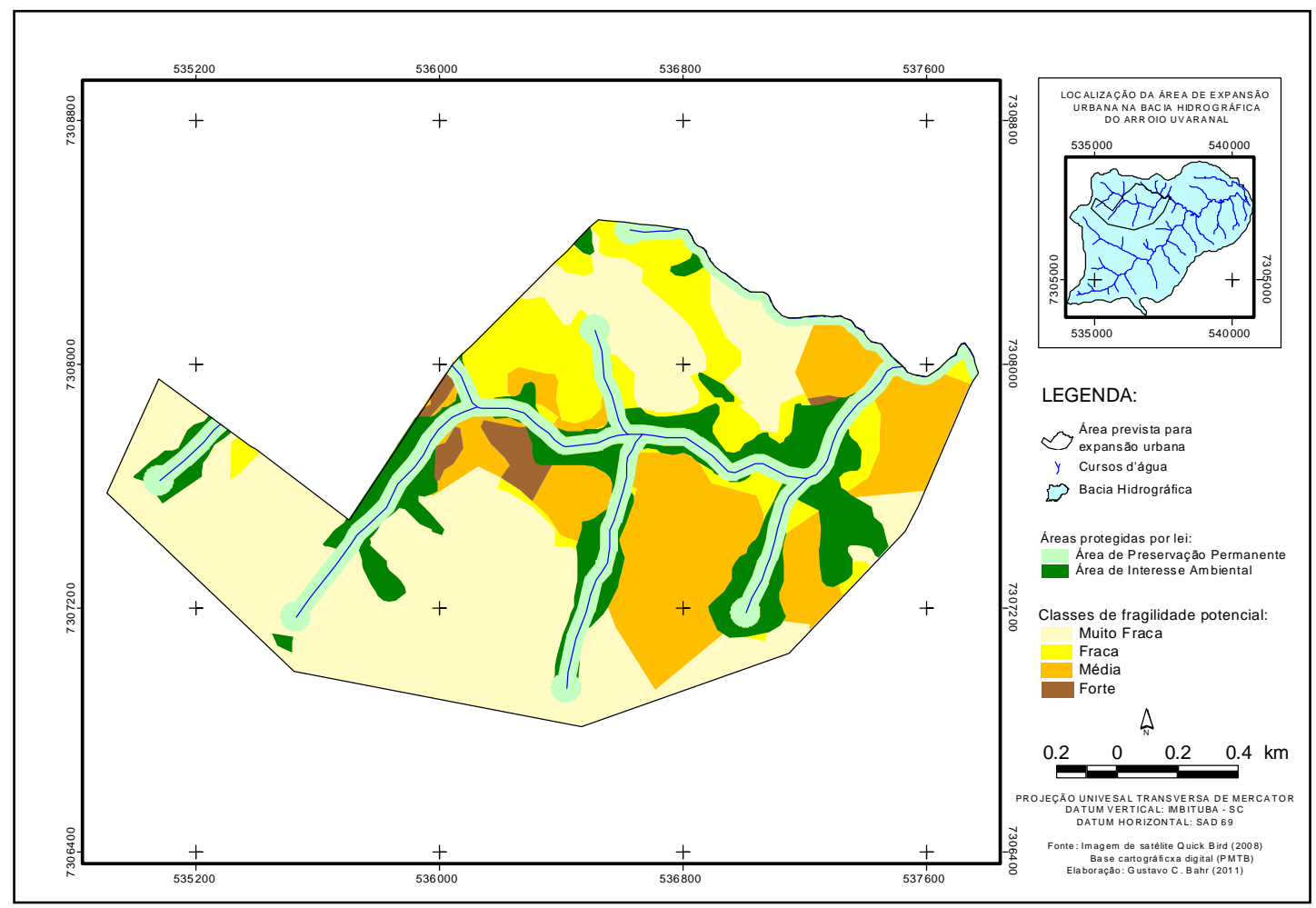

Figura 4. Fragilidade potencial da área de expansão urbana de Telêmaco Borba - PR

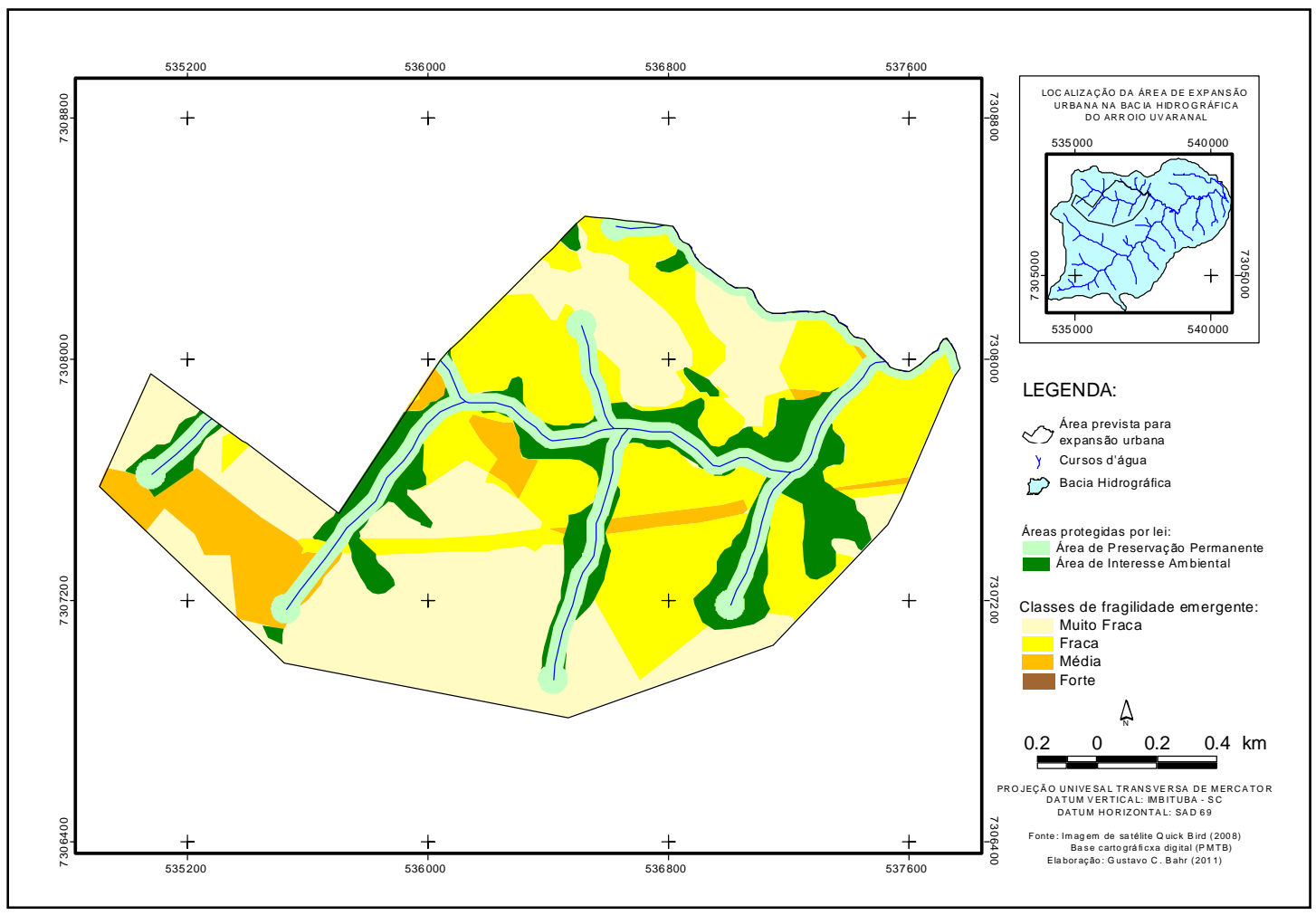

Figura 5. Fragilidade emergente da área de expansão urbana de Telêmaco Borba - PR 
Apesar da quase totalidade da bacia não ultrapassar a classe de fragilidade média, algumas considerações devem ser feitas. Como a maior parte do uso e ocupação na bacia é referente aos reflorestamentos, o que corresponde a 54,30\%, cabe salientar que essa é uma cultura que possui um ciclo que varia em torno de 10 anos. A partir daí são retirados para serem feitos o plantio de novos exemplares, alterando, portanto a fragilidade emergente.

Nesse período, entre a retirada e o novo plantio, o solo fica exposto. $O$ processo de desbaste envolve grande movimentação de maquinário pesado, que necessita de grande poder de tração para sua locomoção, tendendo a revirar a camada superficial do solo, deixando-a mais susceptível para ser carregada pela chuva.

Esta constatação ocorreu entre os meses de janeiro a março de 2011, meses que apresentaram a ocorrência de grande volume pluviométrico. O que se pode perceber foi a ocorrência de uma associação de fatores no agravamento na perda de solo, como a retirada da vegetação, grande movimentação no solo e altos valores pluviométricos.

Destaca-se ainda, a existência de outras áreas que apresentam solos expostos, como a construção de duas grandes edificações, o Hospital Regional e o Centro da Juventude, que já ultrapassam seu prazo de conclusão, o que perdura a exposição do solo, ocasionando assim maior perda pelos processos erosivos verificados in loco. Ainda, a pista de automobilismo e motocross, que além de ser uma área com solo exposto, são destinadas a práticas esportivas que contribuem para a desagregação do solo.

No que diz respeito à área de expansão urbana, esta apresenta mata nativa em bom estado de conservação, indo além da própria APP, motivo pelo qual foi criada a AIA. A respeito da fragilidade potencial, a classe com maior abrangência é a muito fraca, com uma área que representa 57,79\%. Com relação à fragilidade emergente, a classe com maior abrangência é a muito fraca, cobrindo 49,25\% da área total.

Com exceção da APP e da AIA, a área de expansão urbana possui uma área de $1,99 \mathrm{~km}^{2}$, sendo constituída principalmente por reflorestamento. Durante da atribuição dos graus de fragilidade, foi determinada a mesma para 
o reflorestamento e para a área urbanizada, mas em realidade essas são diferentes quanto a conjuntura da dinâmica relacionada aos processos naturais, além dos efeitos ocasionados pela sociedade e seus consequentes reflexos ao ambiente.

Um destaque relevante com relação ao processo de ampliação da área urbana é o período entre a retirada da cobertura presente e a finalização da nova. Nesse período o solo tende a ficar exposto, além de ter a sua camada superficial removida, sendo que o processo é agravado em uma relação direta ao tempo de exposição do solo, apresentando assim maior susceptibilidade a erosão.

A associação de declividades baixas e solos profundos são as mais indicadas com relação a manutenção ambiental, e essa associação é a menos susceptível a ocorrência de processos erosivos. Ainda, visando a manutenção dessa qualidade, a cobertura vegetal é de extrema importância, principalmente a mata, que é a classe de uso e ocupação da terra com melhor grau de cobertura, e posteriormente outras que impeçam o impacto da chuva.

Algumas pequenas áreas de reflorestamento foram identificadas em APP, sendo que o maior problema com relação ao não comprimento da legislação ocorre na área urbana. Várias ocupações foram identificadas nessas áreas, reflexo de um processo de longa data, necessitando de uma política pública que atenda aos reais interesses e necessidades da sociedade.

\section{CONCLUSÃO}

Os resultados obtidos com o trabalho mostraram-se satisfatórios, visto que o objetivo de identificar a fragilidade potencial e emergente da bacia hidrográfica do Arroio Uvaranal foi alcançado, assim como a identificação da fragilidade da área de expansão urbana de Telêmaco Borba.

A metodologia se mostrou inadequada para aplicação na área urbana. Durante a elaboração do mapa de uso e ocupação da terra, para toda área classificada como uso urbanizado foi conferido o mesmo grau de fragilidade. 
Essa determinação levou em conta a impermeabilização do solo e sua consequente proteção contra o embate das gotas das chuvas. Sendo assim, ocorre uma imprecisão nos resultados, pois nem toda área urbanizada possui as características destacadas, pois existem desde áreas que são providas com vegetação até áreas de solo exposto, necessitando, portanto, de adaptações na metodologia.

No que diz respeito à escolha e utilização da bacia hidrográfica como recorte espacial, principalmente como subsídio ao planejamento ambiental, essa se mostrou satisfatória. Esta área apresentou-se ideal na aplicação da metodologia de Ross (2008), por comportar variáveis de análise do estrato natural, que pode ser contrapostas com informações do uso e ocupação da terra, podendo assim determinar a fragilidade potencial e emergente.

Destaca-se, ainda, que a utilização de técnicas de geoprocessamento foi extremamente eficaz, principalmente no cruzamento de informações. Estas técnicas permitem que as informações sejam facilmente atualizadas, reconstituindo e podendo trabalhar com o mais próximo possível da realidade.

Mesmo com as questões destacadas, o estudo da fragilidade ambiental na Bacia do Uvaranal mostrou-se de extrema importância, justamente porque essa é uma área que apresenta uma dinâmica em seu uso. As considerações das análises antes da ampliação da área prevista para expansão urbana podem apresentar resultados mais efetivos, do ponto de vista social, econômico e ambiental.

É fato que uma ocupação desordenada tende a ocasionar ou mesmo agravar os processos erosivos, por isto a necessidade de acompanhamento técnico é imprescindível, com análises criteriosas para aprovação de empreendimentos e, sobretudo práticas conservacionistas no processo de implantação dos mesmos.

Assim, pode-se afirmar a importância de uma ocupação ordenada nestas áreas, uma vez que mudanças no cenário atual, tal como a extração da vegetação, acarretaria danos incalculáveis a esse ambiente. Por fim, este trabalho constitui-se em subsídio ao planejamento ambiental através das cartas 
temáticas apresentadas, e devem ser tomadas as decisões necessárias ao processo de gestão do território.

\section{REFERÊNCIAS}

AMCG - Associação dos Municípios dos Campos Gerais. Dados e estatísticas. 2010. Disponível em www.amcg.com.br. Acesso em 22/07/2010.

BERTONI, J.; LOMBARDI NETO, F. Conservação do solo. São Paulo: Ícone, 6. ed., 2008.

BOTELHO, R. G. M.; SILVA, A. S. da. Bacia hidrográfica e qualidade ambiental. In: VITTE, A. C.; GUERRA, A. J. T. (orgs.). Reflexões sobre a geografia física no Brasil. Rio de Janeiro: Bertrand Brasil, 2004, p. 153 - 192.

BRANDÃO, A. M. P. M. Clima urbano e enchentes na cidade do Rio de Janeiro. In: GUERRA, A. J. T.; CUNHA, S. B. (orgs.). Impactos ambientais urbanos no Brasil. Rio de Janeiro: Bertrand Brasil, 5. ed., 2009, p. 47 - 110.

BRASIL. Código Florestal. Lei 4.771 - de 15 de Setembro de 1965.

CAVALHEIRO, F. Urbanização e alterações ambientais. In: SANTOS, D. G. dos.; NUCCl, J. C. Paisagens geográficas: um tributo a Felisberto Cavalheiro. Campo Mourão: FELILCAM, 2009. p. $65-77$.

DIAS, J. E. et al Geoprocessamento aplicado à analise ambiental: o caso do município de Volta Redonda - RJ. In: SILVA, J. X. da; ZAIDAN, R. T. (orgs.). Geoprocessamento e análise ambiental. Rio de Janeiro: Bertrand Brasil, 2006. p. $143-178$.

DONHA, A. G.; SOUZA, L. C. de P.; SUMAGOSTO, M. L. Determinação da fragilidade ambiental utilizando técnicas de suporte à decisão e SIG. Revista Brasileira de Engenharia Agrícola e Ambiental. Campina Grande, v. 10, n. 1, p. $175-181,2006$.

ENGEL, V. L.; PARROTA, J.A. Definindo a restauração ecológica: tendências e perspectivas mundiais. In: KAGEYAMA, P.Y. et al (orgs.) Restauração Ecológica de Ecossistemas Naturais. Editora FEPAF, Botucatu. 340 p. 2003.

GONÇALVES, G. G. G.; DANIEL, O.; COMUNÉLLO, É.; VITORINO, A. C. T.; PEREIRA, H. H. G.; ARAI, F. K. Caracterização empírica da fragilidade ambiental em bacias hidrográficas - o caso da bacia do Rio Dourados - MS. Anais: 2 S Simpósio de Geotecnologias no Pantanal, Corumbá, Embrapa Informática Agropecuária/INPE, p. 422 - 432, 7 - 11 Novembro, 2009. 
GUERRA, A. J. T.; MENDONÇA, J. K. S. Erosão dos solos e a questão ambiental. BOTELHO, R. G. M.; SILVA, A. S. Bacia hidrográfica e qualidade ambiental. In: VITTE, A. C.; GUERRA, A. J. T. Reflexões sobre a geografia física no Brasil. Rio de Janeiro: Bertrand Brasil, 2004. p. 125 - 156.

IBGE. Instituto Brasileiro de Geografia e Estatística. Manual Técnico de Uso da Terra. Série Manuais Técnicos em Geociências, Rio de Janeiro, no 7, 2. ed., 2006, 91p.

KAWAKUBO, F. S.; MORATO, R. G.; CAMPOS, K. C.; LUCHIARI, A.; ROSS, J. L. S. Caracterização empírica da fragilidade ambiental utilizando geoprocessamento. Anais: XII Simpósio Brasileiro de Sensoriamento Remoto, Goiânia, INPE, p. 2203-2210, 16 - 21 Abril, 2005.

KLABIN - Indústrias Klabin. Mapa de solos. Formato digital. 2010.

ROSS, J. L. S. Geomorfologia: ambiente e planejamento. São Paulo: Contexto. 8. ed. 2008.

SANTORO, J. Erosão continental. In: TOMINAGA, L. K.; SANTORO, J.; AMARAL, R. do. (orgs.). Desastres naturais: conhecer para prevenir. São Paulo: Instituto Geológico, 2009. p. 53 - 70.

SPÖRL, C., ROSS, J. L. S. Análise comparativa da fragilidade ambiental com aplicação de três modelos. GEOUSP - Espaço e Tempo, São Paulo, n. 15, p.39 - 49, 2004.

TELÊMACO BORBA. Prefeitura Municipal de Telêmaco Borba. Assessoria Técnica de Planejamento Urbano. Análise Temática Integrada. 2006a, 205 p.

Prefeitura Municipal de Telêmaco Borba. Assessoria Técnica de Planejamento Urbano. Plano Diretor de Desenvolvimento Urbano. 2006b, $138 \mathrm{p}$.

VIEIRA, V. T.; CUNHA, S. B. Mudanças na rede de drenagem urbana de Teresópolis (Rio de Janeiro). In: GUERRA, A. J. T.; CUNHA, S. B. (orgs.). Impactos ambientais urbanos no Brasil. Rio de Janeiro: Bertrand Brasil, 5. ed., 2009, p. $111-145$. 